\title{
Colonic Obstruction
}

National Cancer Institute

\section{Source}

National Cancer Institute. Colonic Obstruction. NCI Thesaurus. Code C78241.

Blockage of the normal flow of the intestinal contents in the colon. 